\title{
Anti-myostatin Monoclonal Antibody LY2495655
}

National Cancer Institute

\section{Source}

National Cancer Institute. Anti-myostatin Monoclonal Antibody LY2495655. NCI

Thesaurus. Code C99640.

A monoclonal antibody against myostatin (MSTN) with potential anti-cachexia activity. Upon administration, anti-myostatin monoclonal antibody LY2495655 binds to and neutralizes the MST N protein, thereby blocking the MSTN signalling pathway. This may help decrease muscle protein breakdown and muscle weakness and may attenuate cancer cachexia. MST N, a member of the transforming growth factor-beta (T GF-beta) superfamily, is a negative regulator of muscle growth and development. 